\title{
The heat transfer and instabilities results during the onset of flow boiling in minichannels
}

\author{
Beata Maciejewska ${ }^{1,{ }^{*}, \text { Magdalena Piasecka }}{ }^{1}$, and Artur Piasecki ${ }^{2}$ \\ ${ }^{1}$ Kielce University of Technology al. Tysiaclecia Panstwa Polskiego 7, 25-314 Kielce, Poland \\ ${ }^{2}$ Echo Investment S.A., Al. Solidarnosci 36, 25-323 Kielce, Poland
}

\begin{abstract}
The paper discusses the results of flow boiling heat transfer in minichannels obtained on the basis of time-dependent experiments. The main interest of the work was to investigate the occurrence of the accompanying instabilities during the boiling incipience. The essential part of the experimental stand was a test section with two minichannels, each of $1.7 \mathrm{~mm}$ depth. The heated element for FC-72 flowing along the minichannels was a thin foil. In the tested minichannel, the temperature of the outer surface of the foil was measured due to thermoelements. The onset of flow boiling in minichannels was induced by increasing the heat flux supplied to the heater. The main aims of the investigation were to determine the heat transfer coefficient by means of the FEM with time-dependent Trefftz-type basis functions based on the Hermite interpolation and to recognize dynamic instabilities during boiling incipience. The results were illustrated as: the heat transfer coefficient, the mass flow rate and the inlet pressure versus time and as boiling curves.
\end{abstract}

\section{Introduction}

Extensive studies are carried out to understand mechanisms of heat transfer processes during fluid flow along channels of small cross-sections. These include experimental research and theoretical analysis. The brief review of relevant literature is presented in the authors' earlier works [1-4] which concerned steady-state studies on flow boiling heat transfer in minichannels. This paper focused on flow boiling heat transfer under unsteady state conditions in channels of similar dimensions like in $[5,6]$. In literature the results of experiments concerning time-dependent flow parameters during fluid flow in small gaps are rare. Several examples of works dealing with this topic are [5-11].

Heat transfer coefficient determination belongs to inverse heat transfer problems [12-14]. They could be solved with the use of numerical methods based on the Trefftz method [1-3,15-26]. In the Trefftz method unknown solution to a differential equation is approximated by means of a linear combination of functions strictly satisfying the governing differential equation. In literature a lot of examples of using the Trefftz method for solving: direct [20-22], inverse [1$3,15-18,24-26]$, stationary $[1-3,16,18-19,24]$ and nonstationary $[10,11,15,17,25,26]$ problems can be found.
In this paper, the own 2D time-and-space basis functions in FEM, based on Trefftz functions were constructed. The time-dependent measurements from experiments were used in mathematical method for determining the heat transfer coefficient.

\section{Experimental research}

The schematic diagram of the test section is presented in Fig. 1.

The essential part of the experimental stand is a test section with two minichannels vertically oriented. Each minichannel is $1.7 \mathrm{~mm}$ deep, $16 \mathrm{~mm}$ wide and $180 \mathrm{~mm}$ long. The heated element for FC-72 Fluorinert flowing in minichannels was a thin foil of $0.1 \mathrm{~mm}$ thickness, made of Haynes-230 alloy. In the tested minichannel, the temperature of outer heated foil surface was measured by 18 thermocouples, and in the other minichannel - by an infrared camera. It was possible to observe two-phase flow pattern through a glass panel. Two other thermocouples and two pressure meters were installed at the inlet and outlet of the minichannels. The data from infrared camera were not used to time-dependent study.

\footnotetext{
*Corresponding author: beatam@tu.kielce.pl
} 


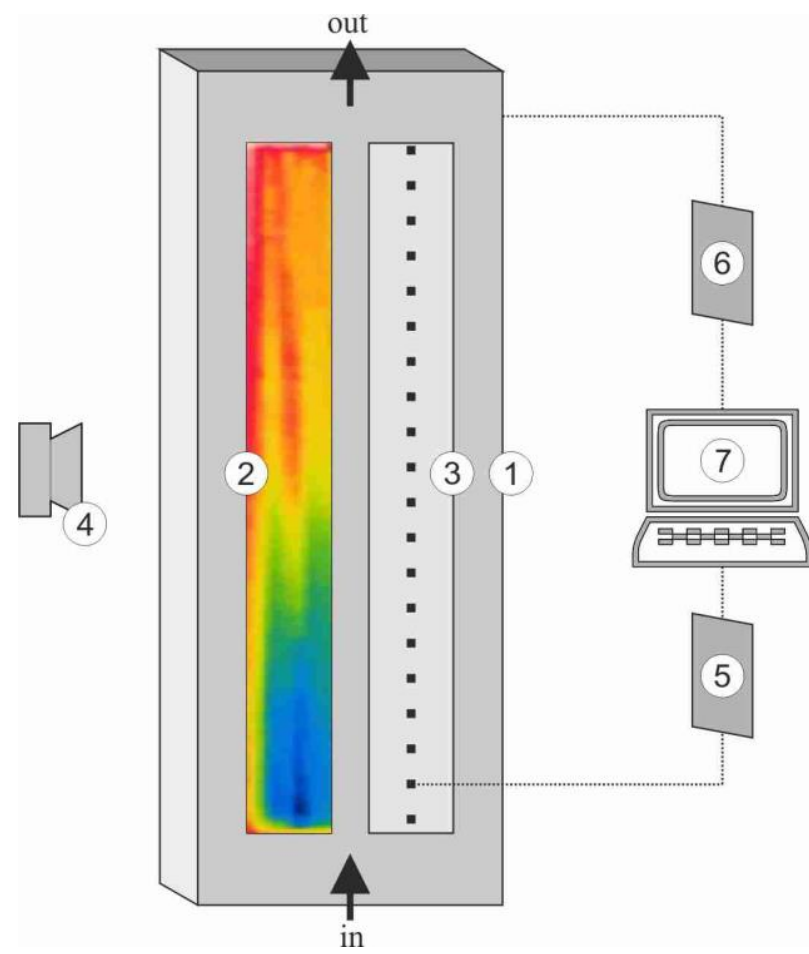

Fig. 1. The schematic diagram of the test section and the data acquisition system, 1 - test section, 2 - auxiliary channel (temperature measurement by infrared camera), 3 - tested minichannel (temperature measurement by thermocouples), 4 - infrared camera, 5 - DaqLab 2005 data acquisition station, 6 - data acquisition station, 7 - PC computer.

\section{Analysis and modelling}

Two-dimensional unsteady state heat transfer in the vertical minichannel was assumed. The temperature variation along the width of the channel was neglected. One dimension refers to the fluid flow direction and the second dimension is normal to it and corresponds with the foil thickness. Only the subcooled boiling region with onset of boiling during fluid flow through the minichannel was analysed. Local heat transfer coefficients were calculated from the Robin boundary condition:

$$
h(x, t)=\frac{-k \frac{\partial T(x, \delta, t)}{\partial y}}{T(x, \delta, t)-T_{f}(x, t)}
$$

where: $k$ is the thermal conductivity of the heated foil, $\delta$ - the thickness of the heated foil, $T$ - the foil temperature, $T_{f}$ - the fluid temperature computed on the basis of the linear distribution of temperature from the inlet to the outlet of the minichannel.

To determine the foil temperature $T$, the inverse problem of heat conduction in the heated foil was formulated by heat equation:

$$
\frac{\partial^{2} T}{\partial x^{2}}+\frac{\partial^{2} T}{\partial y^{2}}-\frac{\rho c_{p}}{k} \frac{\partial T}{\partial t}=\frac{I \Delta U}{A \delta k},(x, y) \in \Omega, t>0
$$

and the initial and the boundary conditions as follows:

$$
T(x, y, 0)=T_{0}(x, y)
$$

$$
\begin{gathered}
\frac{\partial T}{\partial x}(0, y, t)=0 \\
\frac{\partial T}{\partial x}(L, y, t)=0 \\
k \frac{\partial T}{\partial t}(x, 0, t)=q_{\text {loss }}^{\prime \prime}(t) \\
T\left(x_{p}, 0, t_{m}\right)=T_{p}\left(t_{m}\right), p=1,2 \ldots P ; m=1,2 \ldots M
\end{gathered}
$$

where: $\Omega=\left\{(x, y) \in R^{2}: 0<x<L, 0<y<\delta\right\}$, $L$ - length of the heated foil, $\rho$ - density of the heated foil, $c_{p}$ - specific heat of heated foil, $I-$ the current supplied to the heated foil, $\Delta U$ - the drop in voltage along the length of the heated foil, $A$ - surface area of the heated foil in contact with the fluid, $q_{\text {loss }}^{\prime \prime}$ - heat losses to the surroundings, estimated as in [19], $T_{p}$ - foil temperature measurements obtained from thermocouples, $P$ - number of measurements, $M$ number of time intervals, $k, \delta$ - defined as for Eq. (1).

The inverse problem, Eqs. (2-7), was solved by the FEM with the time - dependent Trefftz type basis functions obtained with the use of the Hermite interpolation, like in [1].

\section{Results and discussion}

The study was focused on the heat transfer coefficient determination on the basis of time-dependent experimental measurements. Local values of this coefficient are obtained by solving the inverse heat conduction problem using the FEM based on Trefftztype basis functions in time-space subdomains. The heat transfer coefficient dependence as a function of time, in the region of boiling incipience and subcooled boiling, was illustrated in Fig. 2. It was determined on the basis of temperature measurements by selected thermocouples: $\mathrm{T}_{6}$ and $\mathrm{T}_{15}$.

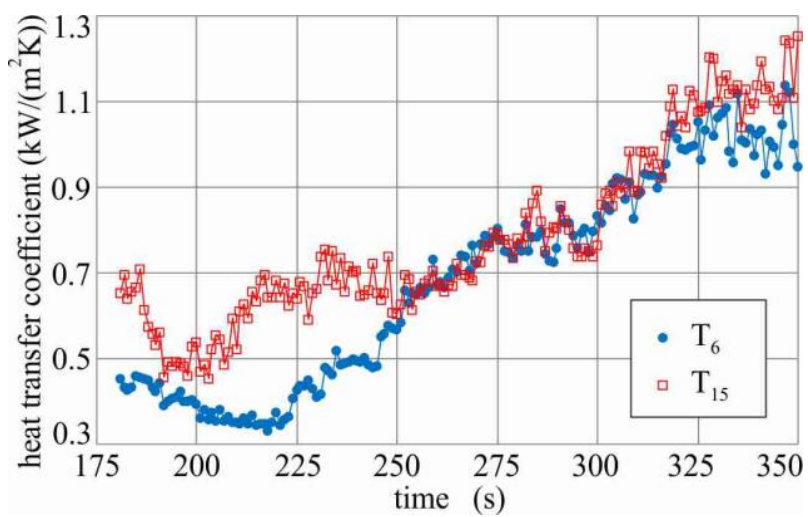

Fig. 2. The heat transfer coefficient dependence as a function of time, calculated on the temperature measurement by thermocouples Nos. $\mathrm{T}_{6}$ and $\mathrm{T}_{15}$.

During the analysis of time-dependent values of the heat transfer coefficient in the region of boiling incipience and subcooled boiling, it was found that local coefficients had relatively low values. The values of coefficient increased with time - and also with increasing of heat flux value supplied to the heater. The 
highest difference of the heat transfer coefficient values was observed in the range $0.3-0.7 \mathrm{~kW} /\left(\mathrm{m}^{2} \mathrm{~K}\right)$ and significant scatter of the results was occurred at the end of analyzed time interval.

The results are presented in Fig. 3 as relationships between the heat flux and the difference between heated foil and fluid temperatures, known as boiling curves. These curves were plotted for two selected distances from the minichannel inlet where thermocouples $\mathrm{T}_{6}$ and $\mathrm{T}_{15}$ were placed. The data were collected while the heat flux supplied to the heated foil was being increased and later decreased.

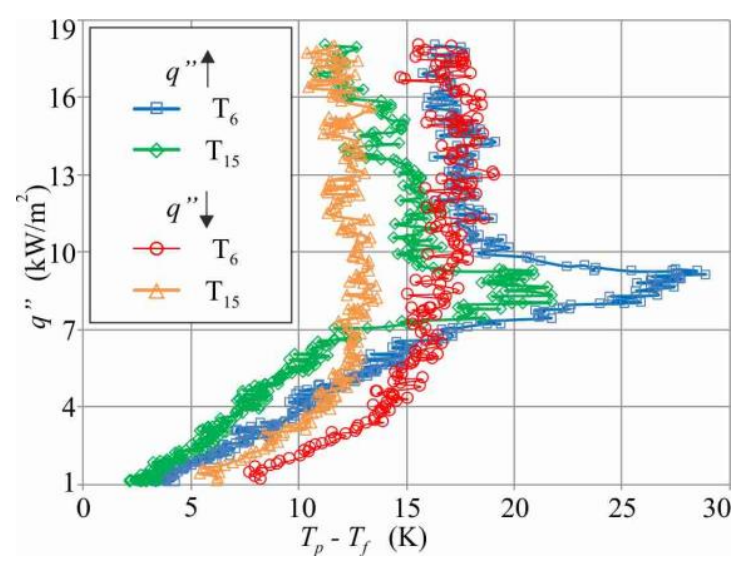

Fig. 3. Boiling curves constructed for two selected distances from the minichannel inlet where thermocouples $T_{6}$ and $T_{15}$ were placed.

The constructed boiling curves are typical in shape. Spontaneous nucleation at boiling incipience caused a drop in the temperature of the heated surface, the phenomenon known as "nucleation hysteresis" [1].

The arrangement of points on the curves presents high scatter. The higher temperature drops characteristic for boiling incipience are observed in boiling curve plotted for the distance where thermocouple T6 were mounted (near the inlet).

The instabilities of fluid pressure and mass flux are analysed widely as an accompanying the flow with change of phase e.g. in [10].

It should be underlined that during the experiment mass flow rate was kept nearly constant while heat flux was gradually increased. It is observed that with increasing heat flux, pressure slightly increased. The results are presented in Fig. 4 and Fig. 5, as mass flow rate or inlet pressure as a function of selected time ranges (part a: time interval in the range 199-212 s, part b: time interval in the range $217-230 \mathrm{~s}$ ) as follows:

- mass flow rate measured by Coriolis mass flow meter, dependences as a function of time - Fig. 4 ,

- $\quad$ inlet pressure measured by pressure meter at the inlet, dependences as a function of time - Fig. 5.
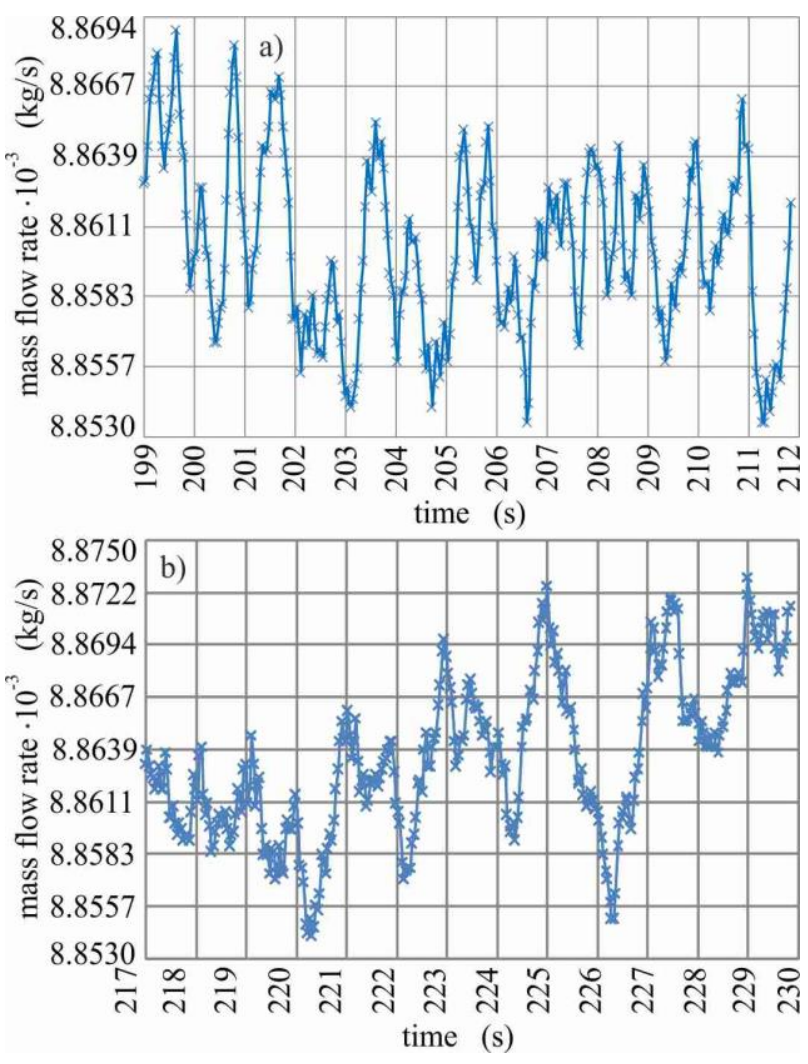

Fig. 4. The mass flow rate dependences as a function of time: a) time interval $199-212 \mathrm{~s}, \mathrm{~b}$ ) time interval $217-230 \mathrm{~s}$.
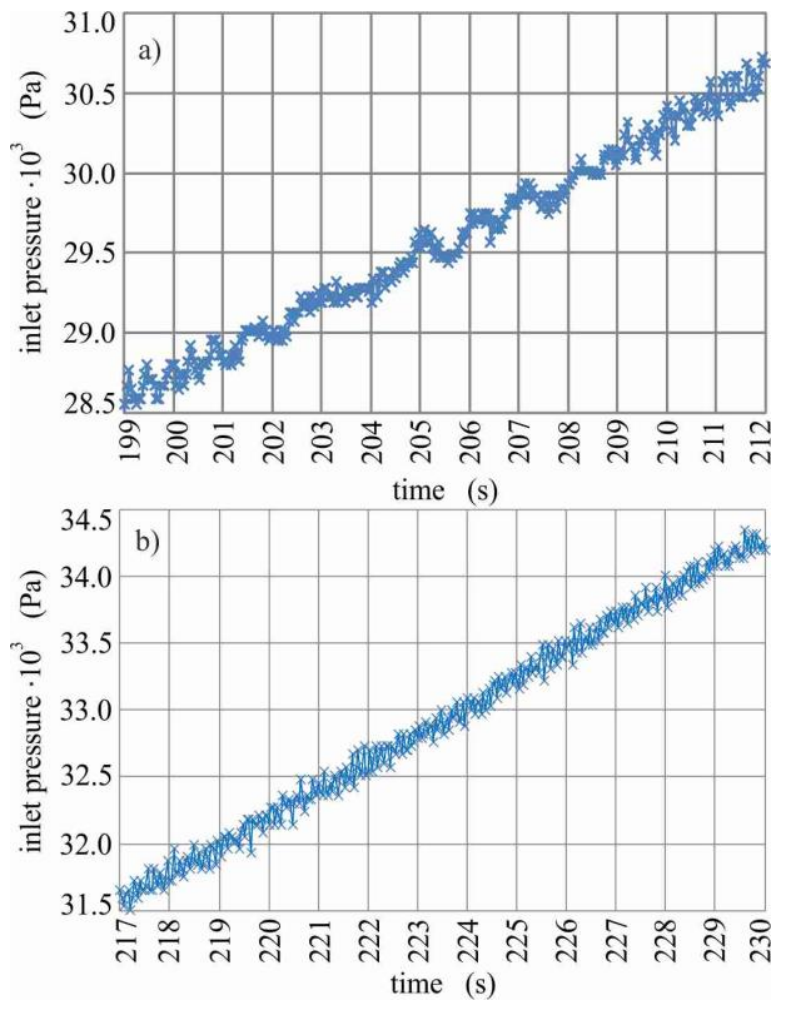

Fig. 5. The inlet pressure dependences as a function of time: a) time interval $199-212 \mathrm{~s}, \mathrm{~b}$ ) time interval $217-230 \mathrm{~s}$.

It was noticed that the instabilities in mass flow rate during the onset of flow boiling have a wave-like nature. They are related to the change of the mass flow density (density-wave instability) and often occur with pressure- 
drop instabilities. The oscillation character of pressure instabilities observed by other authors (as in [27]), need to be analysed deeply on the basis of a wide range of experimental data. The observed phenomena could be compared with literature as with the results of mathematical modelling discussed in [28-31].

\section{Conclusions}

The method of solving the nonstationary inverse heat transfer problem using the FEM with time-dependent Trefftz-type basis functions obtained on the basis of the Hermite interpolation were discussed in this paper. This method was used in calculations concerning heat transfer coefficient determination on the basis of the timedependent study on flow boiling heat transfer in minichannels. The proposed method can be useful to solve non-stationary inverse problems described by linear differential equations. It allows to determine the value of unknown function and its derivatives at nodes of a time-space mesh. Calculations were provided on the basis of experimental data. During experiment the temperature of the outer surface of the heated element for FC-72 flowing along the tested minichannel was measured by thermoelements. The onset of flow boiling was induced by increasing the heat flux supplied to the heater. It was found that local heat transfer coefficients had relatively low values up to $1300 \mathrm{~W} /\left(\mathrm{m}^{2} \mathrm{~K}\right)$ and their values increased with time and with increasing of heat flux. The constructed boiling curves were typical in shape with visible drop in the temperature of the heated surface at the onset of boiling.

The main interest of the work was also to investigate the occurrence of the accompanying instabilities of mass flow and pressure on the boiling incipience. The character of observed instabilities were presented and shortly discussed. They need to be analysed deeply on the basis of a wide range of experimental data.

The research reported herein was supported partially by a grant from the Polish National Science Centre (No. NCNM. ZKIS.18.0010400600/2.02.03.01.0020 2018/02/X/ST8/01271)

\section{References}

1. B. Maciejewska, M. Piasecka, Heat Mass Transf. 53, 1211-1224 (2017)

2. K. Strąk, M. Piasecka, B. Maciejewska, Int. J. Heat Mass Transf. 117, 375-387 (2018)

3. B. Maciejewska, K. Strąk, M. Piasecka, Int. J. Numer. Methods Heat Fluid Flow. 28, 206-219 (2018)

4. M. Piasecka, K. Strąk, B. Grabas, Arch. Metall. Mater. 62, 1983-1990 (2017)

5. A. Majumder, B. Mehta, S. Khandekar, Int. J. Therm. Sci. 66, 8-18 (2013)

6. B. Mehta, S. Khandekar, Int. J. Therm. Sci. 91, 157-166 (2015)

7. Z. Zhou, X. Xu, X. Liang, Exp. Therm. Fluid Sci. 34, 1409-1414 (2010)
8. J. Taler, B. Wójtowicz, Arch. Thermodyn. 28, 3-14 (2007)

9. P. Ocłoń, S. Łopata, M. Nowak, Heat Mass Transf. 51, 553-566(2015)

10. B. Maciejewska, M. Piasecka, Int. J. Heat Mass Transf. 107, 925-933 (2017)

11. B. Maciejewska, M. Piasecka, Int. J. Numer. Methods Heat Fluid Flow, doi:10.1108/HFF-122018-0781 (2019)

12. A.N. Tikhonov, V.Y. Arsenin, Solution of ill-posed problems (Wiley, New York, 1977)

13. J. V. Beck, B. Blackwell, C.R. St. Clair, Inverse heat conduction. Ill-posed Problems (Wiley Interscience, New York, 1985)

14. M.N. Özisik, H.R.B. Orlande, Inverse heat transfer: fundamentals and applications. Fundamentals and Applications (Taylor \& Francis, New York, 2000)

15. E. Trefftz, Int. Kongress für Tech. Mech., Zürich, 131-137 (1926)

16. I. Herrera, Numer. Methods Partial Differ. Equ. 16, 561-580 (2000)

17. V. Kompis, F. Konkol, M. Vasko, Comput. Assist. Mech. Eng. Sci. 8, 385-395 (2001)

18. Z.-C. Li, T.-T. Lu, H.-T. Huang, H.-D. Cheng Alexander, Numer. Methods Partial Differ. Equ. 23, 1-52 (2006)

19. K. Grysa, A. Maciag, A. Pawinska, Int. J. Heat Mass Transf. 55, 7336-7340 (2012)

20. M. Cialkowski, J. Therm. Sci. 11，163-171 (2002)

21. M. Cialkowski, K. Grysa, J. Inverse Ill-posed Probl. 18, 595-616 (2010)

22. K. Grysa, B. Maciejewska, J. Theor. Appl. Mech. 51, 251-264 (2013)

23. S. Hozejowska, R. Kaniowski, M.E. Poniewski, Exp. Therm. Fluid Sci. 78 18-29 (2016)

24. A. Maciag, Int. j. numer. method. biomed. eng. 27, 1107-1125 (2011)

25. S. Blasiak, A. Pawinska, Int. J. Heat Mass Transf. 90, 710-718 (2015)

26. M. Piasecka, K. Strąk, B. Maciejewska, Heat Transf. Eng. 38, 332-346 (2017)

27. H. Grzybowski, R. Mosdorf, Int. J. Heat Mass Transf. 73, 500-510 (2014)

28. W. Kuczynski, T. Bohdal, J.P. Meyer, et al, Int. J. Heat Mass Transf. 141, 1025-1035 (2019)

29. W. Kuczynski, A. Denis, Int. J. Heat Mass Transf. 131, 822-835 (2019)

30. W. Kuczynski, Int. J. Heat Mass Transf. 128, 728738 (2019)

31. W. Kuczynski, Int. J. Heat Mass Transf. 128, 773782 (2019) 